Theme: Eletric Steelworks

\title{
HEAT SIZE UPGRADE IN KROMAN ÇELIK EAF*
}

\author{
Alberto Pesamosca ${ }^{1}$ \\ Orhan Kuran ${ }^{2}$ \\ Luigiandrea Olivieri $^{3}$ \\ Romano Sellan ${ }^{4}$
}

\begin{abstract}
The paper presents the results obtained by the AC EAF supplied by Danieli at Kroman Çelik (Gebze-Turkey) after the planned upgrade to 150 ton. The EAF $7,4 \mathrm{~m}$ diameter, based on the full platform standard design - is able to handle a maximum power of $114 \mathrm{MW}$ and is equipped with the most advanced and reliable technology, including module injection system and the Hireg electrodes regulation system. Excellent results were already obtained with 120 heat size in terms of fast start-up and excellent performance figures. After the upgrade, productivity was increased up to $212 \mathrm{t} / \mathrm{h}$, maintaining high process efficiency $(365 \mathrm{kWh} / \mathrm{t}$ with $\left.32,1 \mathrm{Nm}^{3} / \mathrm{t} \mathrm{O} 2\right)$.

Keywords: EAF; Injection technology; Energy consumption; Heat size.
\end{abstract}

\footnotetext{
Engineer, Process Engineer, Danieli Centro Met, Buttrio, Italy; a.pesamosca@danieli.it. Engineer, Meltshop Manager, Kroman Çelik Sanayii A.Ş, Kocaeli, Turkey.

Engineer, Process Engineer, Danieli Centro Met, Buttrio, Italy; I.olivieri@danieli.it.

Engineer, Executive Vice President Steelmaking, Danieli Centro Met, Buttrio, Italy; r.sellan@danieli.it.
}

* Technical contribution to the $45^{\text {th }}$ Steelmaking Seminar, May $25^{\text {th }}-28^{\text {th }}, 2014$, Porto Alegre, RS, Brazil. 


\section{FURNACE TECHNOLOGICAL FEATURES}

The 120 tons AC, EBT Electric Arc Furnace started operation in July 2010 at Kroman Çelik Sanayii A.Ş. facility (Gebze-Turkey). A 7,4 m bottom shell diameter EAF was installed, considering a future upgrade to 150 tons tapping size.

The EAF is based on the Danieli full-platform standard, with a very compact and performing equipment design, including the following equipments:

- Full mechanical supporting structure

- Shell and roof water cooled panels

- Transformer and serial reactor

- Conductive electrode arms

- Hydraulic unit

- Fastarc® Module Injection System and Catfis manipulator

- Level1 automation system, Including Hireg® regulation

As planned, in July 2012 the EAF was upgraded to 150 tons tapping size. This was achieved modifying refractory profile in order to accommodate the increased steel bath. No other modifications were needed, since EAF was designed taking into account the future upgrade.

The main geometrical features of the furnace are reported below (Table 1).

Table 1. EAF geometrical features

\begin{tabular}{|rc|}
\hline Bottom shell diameter & $7,4 \mathrm{~m}$ \\
\hline Upper shell diameter & $7,2 \mathrm{~m}$ \\
\hline Total liquid steel capacity & $173 \mathrm{ton}$ \\
\hline Height of upper shell panels & $3,0 \mathrm{~m}$ \\
\hline Electrodes diameter & $714 \mathrm{~mm}$ \\
\hline Pitch circle & $1.350 \mathrm{~mm}$ \\
\hline Furnace volume & $140 \mathrm{~m}^{3}$ \\
\hline
\end{tabular}

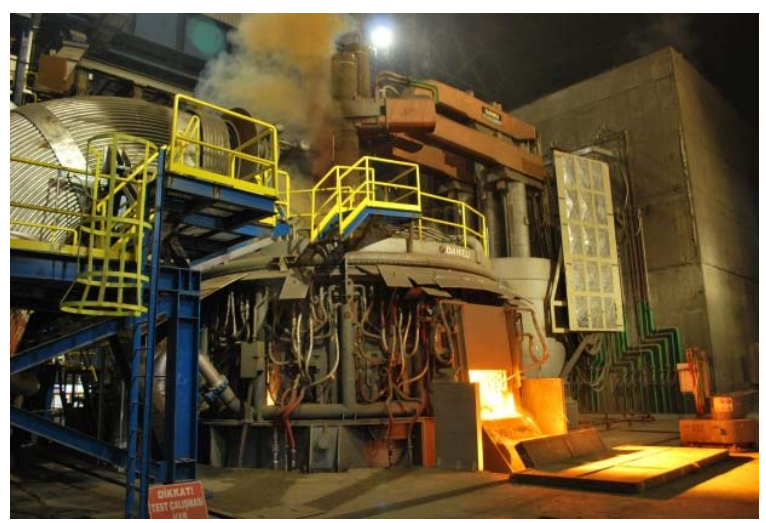

Figure 1. EAF in operation.

The refractory thickness, which was increased in the first phase for tapping 120 tons, was brought back to nominal size in order to accommodate 173 tons.
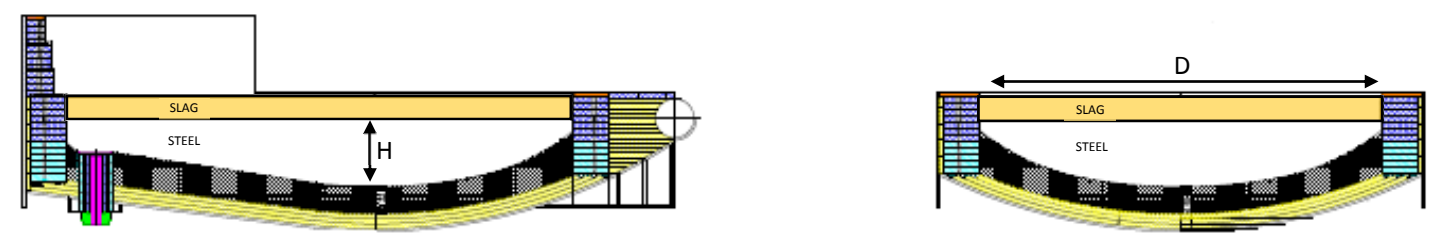

Figure 2. 150 tons EAF refractory design.

\footnotetext{
* Technical contribution to the $45^{\text {th }}$ Steelmaking Seminar, May $25^{\text {th }}-28^{\text {th }}, 2014$, Porto Alegre, RS, Brazil.
} 
The comparison between main geometrical data is reported in the following table.

Table 2. Comparison of geometrical data before and after heat size upgrade

\begin{tabular}{|r|c|c|}
\hline & $\mathbf{1 2 0}$ ton & $\mathbf{1 5 0}$ ton \\
\hline Bottom heart thickness & $\mathbf{7 5 0} \mathbf{~ m m}$ & $650 \mathrm{~mm}$ \\
\hline Wall thickness & $626 \mathrm{~mm}$ & $526 \mathrm{~mm}$ \\
\hline $\mathrm{D}$ & $6,15 \mathrm{~m}$ & $6,35 \mathrm{~m}$ \\
\hline $\mathrm{H}$ & $0,90 \mathrm{~m}$ & $1,00 \mathrm{~m}$ \\
\hline $\mathrm{H} / \mathrm{D}$ & 0,146 & 0,158 \\
\hline
\end{tabular}

Electrical power is supplied by a 154-kV line, with meltshop being fed at 34,5-kV through a step-down transformer. The medium-voltage busbar system is equipped with a Static Var Compensation System, which is made up of four filter banks with a total compensation power of $180 \mathrm{MVar}$. The bank is designed and dimensioned to handle low-frequency harmonics.

The AC furnace is fed by a 140-MVA transformer and Serial Reactor, with on-load tap changer. In this way a high level of voltage control is achieved in all stages of perforation, melting and refining. Moreover, a progressive melting profile can be set in order to obtain a stable use of high arc voltages. No modifications were performed on the transformer during the upgrade.

The set points of electrical and chemical profile are managed automatically according to the different stages of melting. The utilization of Hireg® for electrode regulation allows for high utilization of available power.

Table 3. Electrical supply data

\begin{tabular}{|rcl|}
\hline HV / MV rated voltage & $154 / 34,5$ & kV \\
\hline Transformer power /overload & $140 / 0$ & MVA \\
\hline Low voltage range & $1353 / 846$ & $\mathrm{~V}$ \\
\hline Operating current & $55 / 65$ & $\mathrm{kA}$ \\
\hline
\end{tabular}

Table 3 summarizes the nominal capacity of More Module Chemical Package. The arrangement of injectors is shown in Figure 3.

The injectors on the side-wall are installed in copper bulged blocks protruding into the furnace in order to reach the optimum position in terms of oxygen/carbon stream length and vertical/horizontal angles.

Table 4. Modules data

\begin{tabular}{|r|c|c|c|}
\hline & $\begin{array}{c}\text { Oxygen nominal } \\
\text { flowrate }\left(\mathrm{Nm}^{3} / \mathrm{h}\right)\end{array}$ & $\begin{array}{c}\text { Carbon flowrate } \\
(\mathrm{kg} / \mathrm{min})\end{array}$ & Burner power (MW) \\
\hline OXYGEN JET 1-2-4-5 & 2.300 & - & 4,0 \\
\hline OXYGEN JET 3 & 2.300 & - & 4,0 \\
\hline JET 1-2 & - & - & 4,0 \\
\hline CARBON PIPES 1-2-3 & - & 40 & - \\
\hline
\end{tabular}

The injector in the EBT area is installed on a horizontal panel and is projected into the furnace in order to establish a proper distance between steel level and injector's tip.

The Oxygen Jet injector is capable of generating a highly coherent supersonic stream of oxygen that remains constant up to the steel bath, thanks to the special design of the nozzle and to the shrouding and Mixed Swirled Flame (MSF) technologies. The MSF significantly helps to minimize the risk that unburned natural

\footnotetext{
* Technical contribution to the $45^{\text {th }}$ Steelmaking Seminar, May $25^{\text {th }}-28^{\text {th }}, 2014$, Porto Alegre, RS, Brazil.
} 
gas flows through the scrap pile producing endothermic reactions through dissociation of gas compounds. In order to provide an adequate operational flexibility, each injector has a dedicated control.

Carbon injection is provided by three carbon lances installed in the same Oxygen Jet bulged block and distributed all around the surface of the bath. The carbon lances inject carbon fines just inside the slag layer in order to better achieve the reduction of $\mathrm{FeO}$ and $\mathrm{MnO}$ and for the subsequent $\mathrm{CO}$ gas generation that promotes slag foaming.

During bucket melting burner phase is adopted to enhance scrap melting around the walls and allow better oxygen injection efficiency during lance phase. During last stages of burner phase, fuel flow rate is decreased and high ratio $\mathrm{O} 2 / \mathrm{CH} 4$ is used, in order to avoid excessive heat losses and enhance cutting of scrap pieces. In the last stages of bucket melting and during refining Oxygen Jets are employed together with carbon injection, which is very important during flat bath phase because it avoids excessive slag oxidation, thus keeping good slag foaming up to the end of the process.

No interruption of power-on occurs during refining, due to utilization of CATFIS automatic sampler that operates through the slag door. It was installed to improve operators' safety by eliminating manual operation.

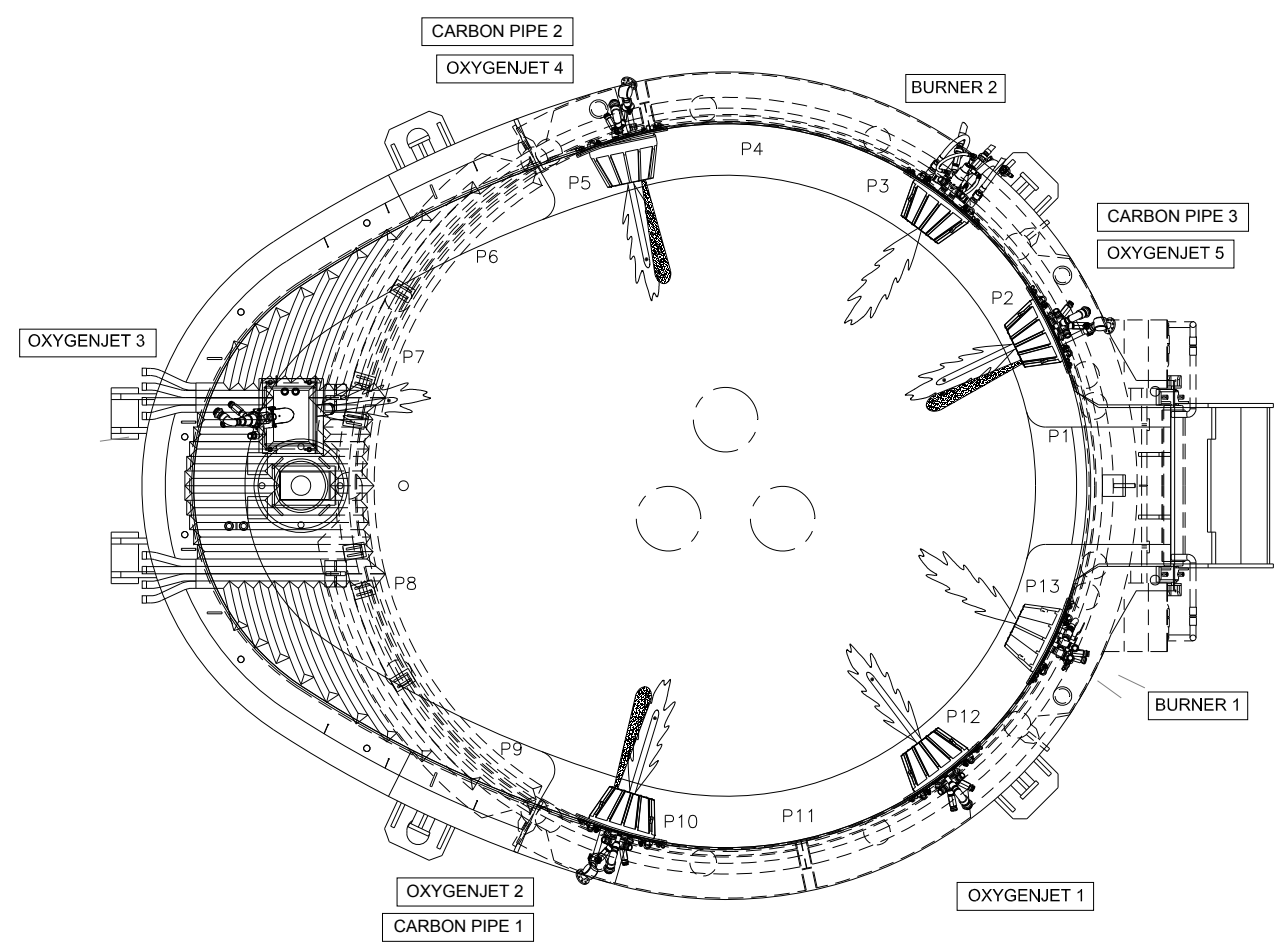

Figure 3. Modules layout.

\section{FURNACE PRODUCTIVITY}

Excellent results are being obtained in terms consistency and repeatability of EAF performances. This is shown by the average daily tap to tap (Figure 4).

* Technical contribution to the $45^{\text {th }}$ Steelmaking Seminar, May $25^{\text {th }}-28^{\text {th }}, 2014$, Porto Alegre, RS, Brazil. 

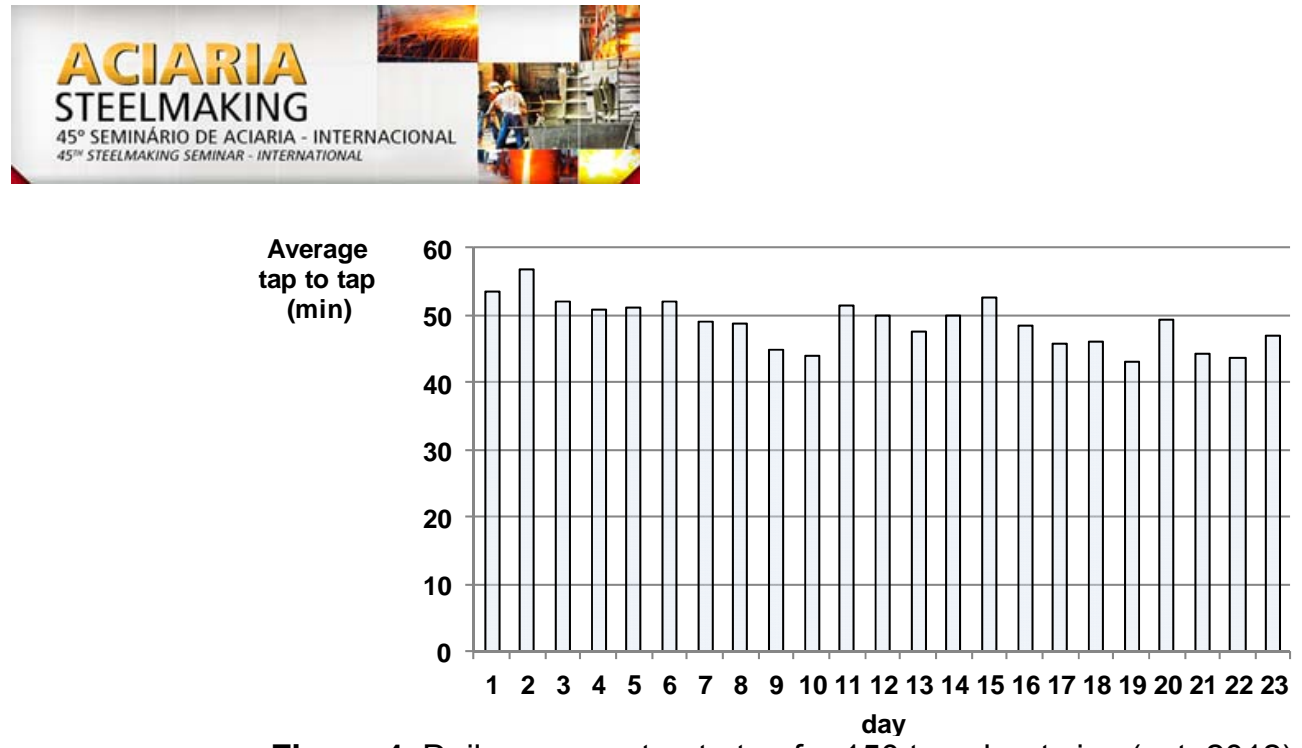

Figure 4. Daily average tap to tap for 150 tons heat size (oct. 2012).

After the upgrade consistent performances were soon reached thanks to furnace flexibility and excellent operational skillness by Kroman personnel, that made it possible to obtain fine process regulation. The best result in terms of productivity is 34 heats/day (October 19th), which means an average of $212 \mathrm{ton} / \mathrm{h}$. The trend of furnace productivity from start-up is reported in Figure 5, based on best daily performances.

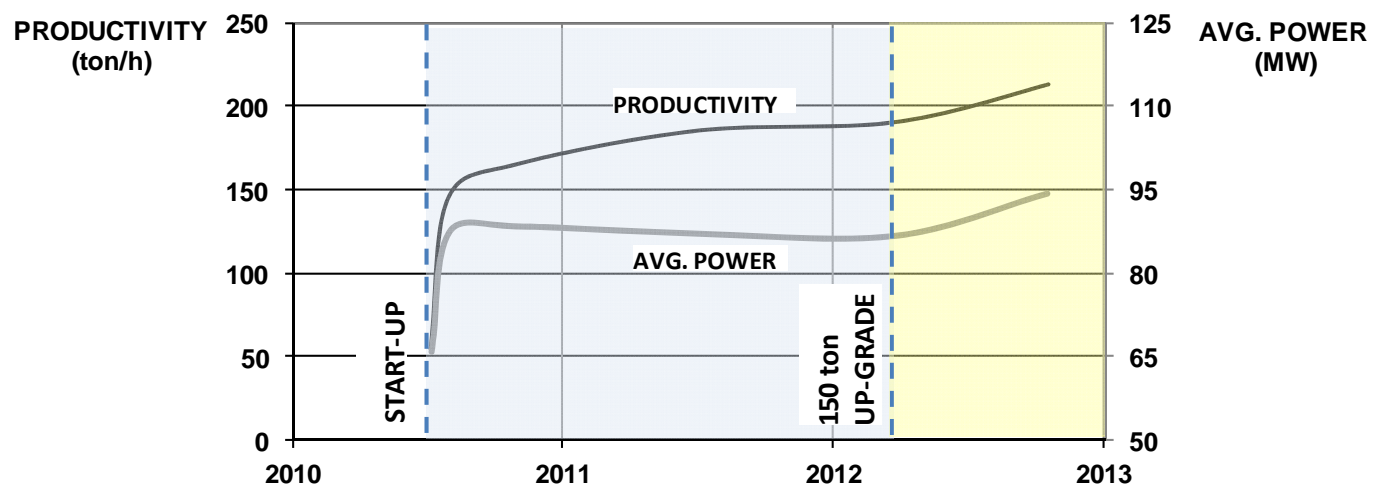

Figure 5. EAF productivity and electric power input trends based on best daily averages

In the first two years after start-up, a continuous increase of EAF productivity was obtained, this being mainly due to power-off minimization. After 150 tons up-grade, a slight increase of power-off was experienced due to the need of 3 buckets practice (two or three buckets practice was adopted until the upgrade). Furnace productivity increase is mainly due to higher power being applied. Maximum power employed during melting stage is $109 \mathrm{MW}$ (Varc $591 \mathrm{~V}$, RWI $240 \mathrm{kVW} / \mathrm{cm}^{2}$ ).

\section{SLAG PRACTICE}

In order to maximize productivity, average power was increased from $87 \mathrm{MW}$ to $95 \mathrm{MW}$. As a consequence, process conditions became more aggressive for the refractory walls, because of the increased radiation. Thus, it became mandatory to monitor and modify the slag chemistry in order to limit refractory wear. Right slag composition also permits good foaming, required to protect the refractories during flat bath phases. For this reason Lime and Dololime additions were increased up to the average values of $52 \mathrm{~kg} / \mathrm{t}$ and $6 \mathrm{~kg} / \mathrm{t}$ respectively, in order to achieve proper basicity and to increase $\mathrm{MgO}$ content. Also, average FeO content was decreased down to $20.5 \%$. After a period of slag sampling and process additions' calibrating, the slag average chemical composition reported in Table 7 has been obtained.

\footnotetext{
* Technical contribution to the $45^{\text {th }}$ Steelmaking Seminar, May $25^{\text {th }}-28^{\text {th }}, 2014$, Porto Alegre, RS, Brazil.
} 
Table 5. Slag chemical composition

\begin{tabular}{|c|c|c|c|c|c|c|}
\hline $\mathrm{CaO} \%$ & $\mathrm{MgO} \%$ & $\mathrm{SiO}_{2} \%$ & $\mathrm{Al}_{2} \mathrm{O}_{3} \%$ & $\mathrm{FeO} \%$ & $\mathrm{MnO} \%$ & $\mathrm{IB} 3$ \\
\hline 41,5 & 5,6 & 19,7 & 7,0 & 20,5 & 5,7 & 1,6 \\
\hline
\end{tabular}

According to Pretorius, the slag obtained through the new practice has optimal foaming properties, that can be deducted from the isothermal solubility diagram (Figure 6) for a basicity index IB3=1,75 (very similar to the 150t furnace slag IB3=1,6). The position of the Kroman slag after 150t upgrading is indicated by the blue star in the figure, which is very close to the dotted line representing the compositions related to best foaming properties.

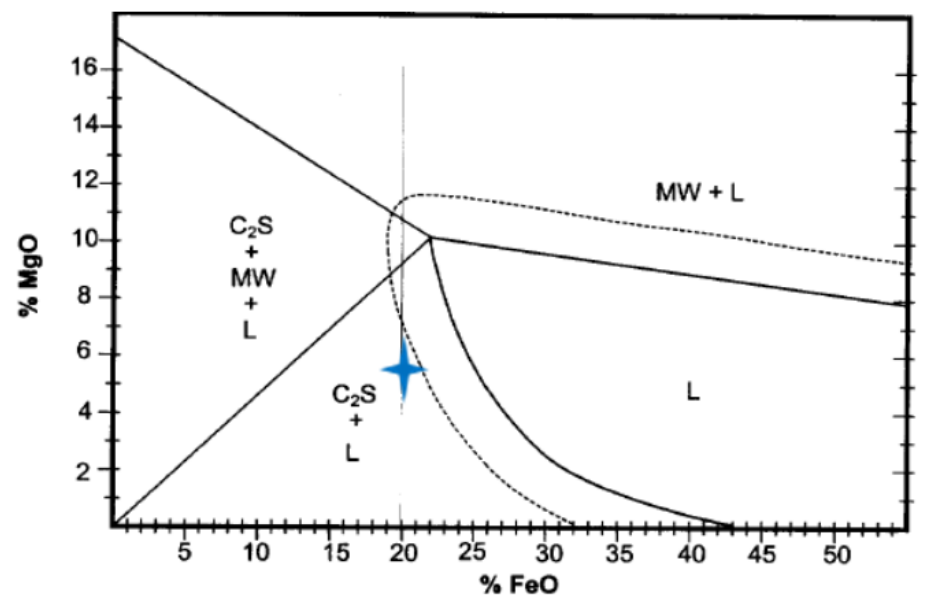

Figure 6. Isothermal solubility diagram for a basicity index IB $3=1,75$. The dotted line indicates the region for the best foaming properties; the blue star indicates the composition of the $150 t$ process slag.

\section{CONSUMPTION FIGURES}

In Tab. 6 the specific consumptions data for 150 tons is reported, based on the best daily average achieved.

Table 6. Best daily averages for 150 t heat size (October $21^{\text {st }} 2012$ )

\begin{tabular}{|rcc|}
\hline \multicolumn{3}{|c|}{ Daily Averages } \\
\hline Bucket & 3 & {$[\#]$} \\
\hline Tapped steel & 149.1 & {$[\mathrm{tls}]$} \\
\hline Yield & 89.7 & $\%[\mathrm{tls} / \mathrm{tch}]$ \\
\hline Tap to Tap & 44.4 & {$[\mathrm{~min}]$} \\
\hline Power On & 34.6 & {$[\mathrm{~min}]$} \\
\hline Avg Power & 94.4 & {$[\mathrm{MW}]$} \\
\hline Electric Energy cons. & 365 & {$[\mathrm{kWh} / \mathrm{tls}]$} \\
\hline Natural gas cons. & 5.9 & {$\left[\mathrm{Nm}^{3} / \mathrm{tls}\right]$} \\
\hline Oxygen cons. & 32.1 & {$\left[\mathrm{Nm}^{3} / \mathrm{tls}\right]$} \\
\hline Charged carbon cons. & 10.0 & {$[\mathrm{~kg} / \mathrm{tls}]$} \\
\hline Injected carbon cons. & 9.9 & {$[\mathrm{~kg} / \mathrm{tls}]$} \\
\hline Pig iron in charge & 4.5 & $\%$ \\
\hline Lime & 43.6 & {$[\mathrm{~kg} / \mathrm{tls}]$} \\
\hline Dololime & 6.7 & {$[\mathrm{~kg} / \mathrm{tls}]$} \\
\hline Total Energy Input $\left({ }^{*}\right)$ & 701 & {$[\mathrm{kWh} / \mathrm{tls}]$} \\
\hline
\end{tabular}

$\left(^{*}\right)$ complete combustion of carbon to CO2 is considered

\footnotetext{
* Technical contribution to the $45^{\text {th }}$ Steelmaking Seminar, May $25^{\text {th }}-28^{\text {th }}$, 2014, Porto Alegre, RS Brazil.
} 
The total specific energy inputs and outputs referred to 150 tons heat size are represented in Figure 7.

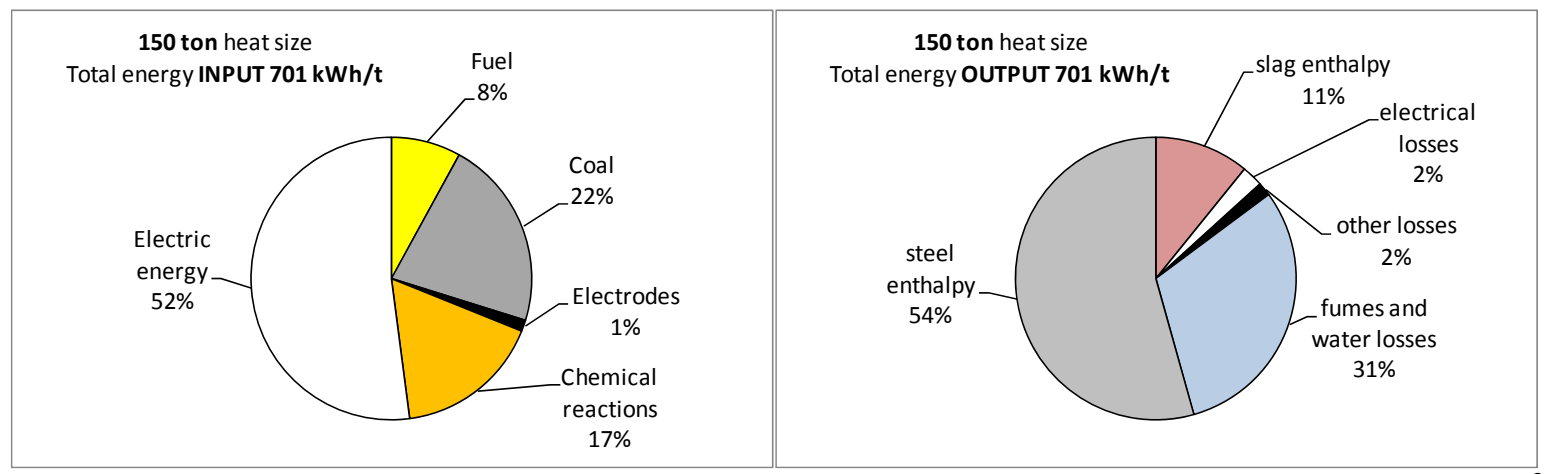

Figure 7. Pie charts representing total energy inputs and outputs for 150 ton heat size (October $21^{\text {st }}$ 2012).

The excellent consumption figures already reached with 120 tons heat size were therefore maintained after up-grade. The process energy efficiency, considered as the ratio between steel-slag enthalpy and total energy inputs, is $65 \%$. In the graph below the trend of main performance indicators is shown.
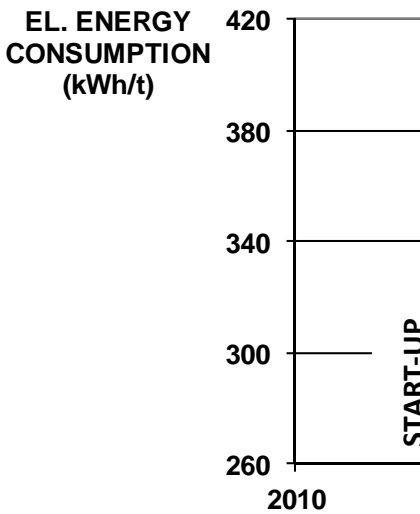

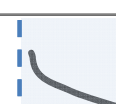
EL. ENERGY
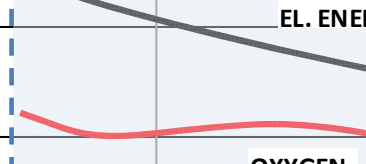

OXYGEN

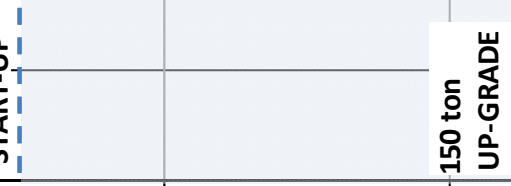

2011

2012

Figure 8. Electric energy and oxygen consumption trends based on best daily averages.

\section{FUTURE IMPROVEMENTS}

Optimization of melting practice resulted in progressive enhancement of EAF performances for 120 tons heat size (Figure 8), therefore some improvements can still be expected for 150 tons operation, even if the absolute results that are now being obtained are really remarkable.

Productivity increase seems to be still feasible because up to now the higher electric power input was handled without damages to refractory and water cooled panels.

It has also to be noted that after up-grade the trend of oxygen consumption decrease has been maintained. This means that the continuous improvement of chemical energy use by melting profile optimization is still a relevant target. In this way, a progressive decrease of environmental impact of EAF process can be achieved, in terms of $\mathrm{CO} 2$ emissions.

For this reasons Kroman Celik, together with Danieli will be once more committed in analyzing further improvements in melting process in order continue the positive performance trend that has been observed since furnace start-up.

* Technical contribution to the $45^{\text {th }}$ Steelmaking Seminar, May $25^{\text {th }}-28^{\text {th }}, 2014$, Porto Alegre, RS, Brazil. 


\section{CONCLUSIONS}

Thanks to the collaboration between Danieli and Kroman Çelik, EAF productivity after up-grade to 150 ton heat size was increased up to $212 \mathrm{t} / \mathrm{h}(+32 \mathrm{t} / \mathrm{h})$.

This was made possible by increasing electric power (average power now being around $95 \mathrm{MW}$ ) and adjusting slag chemistry in order to obtain better foaming and avoid damages or unsustainable wear of the panels and refractory lining.

The relevant results in terms of process efficiency already achieved with 120 tons size were substantially maintained after up-grade. Specific consumptions of electric energy and oxygen are $365 \mathrm{kWh} / \mathrm{t}$ and $32 \mathrm{Nm}^{3} / \mathrm{t}$ respectively. In particular, the trend of oxygen utilization decrease indicates a continuous and successful effort to optimize melting practice.

Still, further improvements can be expected because of the positive trend that has been observed up to now, therefore Kroman Celik and Danieli once more will cooperate in order to set new records for a furnace whose performances can be already considered a benchmark.

* Technical contribution to the $45^{\text {th }}$ Steelmaking Seminar, May $25^{\text {th }}-28^{\text {th }}, 2014$, Porto Alegre, RS, Brazil. 